\title{
DISCONTINUOUS CONDUCTION MODE BUCK CONVERTER WITH HIGH EFFICIENCY
}

\section{Abdul Hakeem Memon}

IICT, Mehran UET, Jamshoro, Sindh, (Pakistan).

E-mail: hakeem.memon@faculty.muet.edu.pk

ORCID: https://orcid.org/0000-0001-8545-3823

\section{Rizwan Ali}

IICT, Mehran UET, Jamshoro, Sindh, (Pakistan).

E-mail: rizwanalimemon26@gmail.com

ORCID: https://orcid.org/0000-0002-3022-6356

Zubair Ahmed Memon

IICT, Mehran UET, Jamshoro, Sindh, (Pakistan).

E-mail: zubair.memon@faculty.muet.edu.pk ORCID: https://orcid.org/0000-0001-5967-3152

\section{Citación sugerida:}

Memon, A. H., Ali, R., y Memon, Z. A. (2021). Discontinuous Conduction Mode Buck Converter with High Efficiency. 3C Tecnología. Glosas de innovación aplicadas a la pyme, Edición Especial, (mayo 2021), 35-51. https://doi.org/10.17993/3ctecno.2021.specialissue7.35-51 


\section{ABSTRACT}

Electronic devices require $\mathrm{AC}$ to $\mathrm{DC}$ converter (rectifier) to convert $\mathrm{AC}$ voltage from the grid to DC voltage for the electronics and its result is low power factor $(\mathrm{PF})$ and harmonic current injection into the system. Nowadays, power factor correction (PFG) converters are being widely used which can achieve high power factor $(\mathrm{PF})$ and reduce the harmonics caused during AC to DC conversion and buck PFC converter is one of mostly used converter. On the other hand, if this converter works with constant duty-cycle (CDG) control scheme, the overall losses are more and efficiency is less. In order to increase the efficiency of buck converter operating in discontinuous conduction mode (DCM), a variable duty-cycle (VDG) control scheme is proposed. The method of fitting VDC control scheme is given for making implementation of circuit simpler. The performance of buck converter is compared with CDC and VDC control scheme in terms of efficiency. For verifying the validity of proposed technique, the simulation results are carried out. The object of the research paper is to propose the control scheme to achieve high PF for DCM buck converter by only modulating the duty-cycle of buck switch.

\section{KEYWORDS}

Variable Duty-Cycle (VDC), Constant Duty-Cycle (CDG), Discontinuous Conduction Mode (DCM), Electromagnetic Interference (EMI), Duty-Cycle, Buck Converter. 


\section{INTRODUCTION}

Electronic devices require $\mathrm{AC}$ to $\mathrm{DC}$ converter (rectifier) to convert $\mathrm{AC}$ voltage from the grid to DC voltage for the electronics and its result is low power factor $(\mathrm{PF})$ and harmonic current injection into the system. Nowadays, power factor correction $(\mathrm{PFG})$ converters are being widely used which can achieve high power factor $(\mathrm{PF})$ and reduce the harmonics caused during AC to DG conversion (Praneeth \& Williamson, 2018; Williamson, Rathore \& Musavi, 2015; Nussbaumer et al., 2019; Anwar et al., 2017; Al Gabri, Fardoun \& Ismail, 2015; Badawy, Sozer \& De Abreu-Garcia, 2016; Memon et al., 2019a, 2019b, 2019c, 2019d, 2019e).

Power factor correction can be of two types: active PFG and passive PFG. Active PFG can be achieved by using passive elements like inductors, capacitors and inductors and passive PFG can be achieved by using electronic circuits with active switches like insulated gate bipolar junction transistor (IGBT) and metal oxide semiconductor field effect transistor (MOSFET), etc. To obtain the good value of power factor and meet the standards like IEG61000-3-2 and IEEE 519, active power factor correction (PFG) techniques are used. DG to DG converters used as power factor correction circuits with the help of active switches shape the value of supply current which not only improves the PF, but also reduce the harmonics. Among DC-DC converters, DCM buck PFC is generally utilized in many applications because of various advantages like maintaining high efficiency for the wide range of input voltage, cost reduction, low output voltage, protection against inrush current life time improvement and easy design of electromagnetic interference (EMI) filter The major drawback of the buck converter is its PF is low and efficiency is also low, especially when operated with constant duty-cycle control scheme (CDCCS).

For modifying the performance of traditional buck converter, various research has proposed various topologies and control schemes (Endo, Yamashita \& Sugiura, 1992; Lee, Wang \& Hui, 1997; Spiazzi \& Buso, 2000; Huber, Gang \& Jovanovic, 2011; Jang \& Jovanović, 2011; Lamar et al., 2012; Ki \& Lu, 2013; Al Gabri, Fardoun \& Ismail, 2015; Memon et al., 2016; Memon et al., 2017; Memon et al., 2018a, 2018b; Memon et al., 2019a, 2019b, 2019c, 2019d, 2019e; Liu et al., 2020). 
Most of the work in the literature is done to improve the PF of the buck converter. The purpose of this paper is to introduce the control scheme which can improve the efficiency of DGM buck converter.

In this paper, a variable duty-cycle control scheme (VDCCS) is introduced for DCM buck converter to reduce peak and rms current of inductor and hence ultimately enhancing its efficiency.

This paper is divided into six sections. In section 2, the operation states of DCM buck converter are analyzed with traditional CDCCS strategy. The introduced VDCGS is discussed in section 3. Then the comparative analysis is discussed in section 4 in terms of efficiency. In section 5, the effectiveness of proposed topology is evaluated by simulation results. Finally, some conclusions are drawn in section 6.

\section{RESEARCH METHODOLOGY}

The research methodology is based on:

1. Mathematical analysis of the operating principle of the control schemes for DCM Buck converter with the help of MATHCAD converter.

2. Introducing the proposed control scheme to obtain high efficiency

3. Realization of control scheme through control blocks.

4. Comparative analysis of the converter for CDCG and VDCG strategy

5. Developing the simulation model of DGM Buck converter with the help of MATLAB software

6. Confirming the results.

\section{CONVENTIONAL CDC CONTROL SCHEME FOR BUCK CONVERTER}

Figure 1(b) shows the main circuit of a buck converter with CDC control scheme.

The input voltage before and after the bridge are given as 


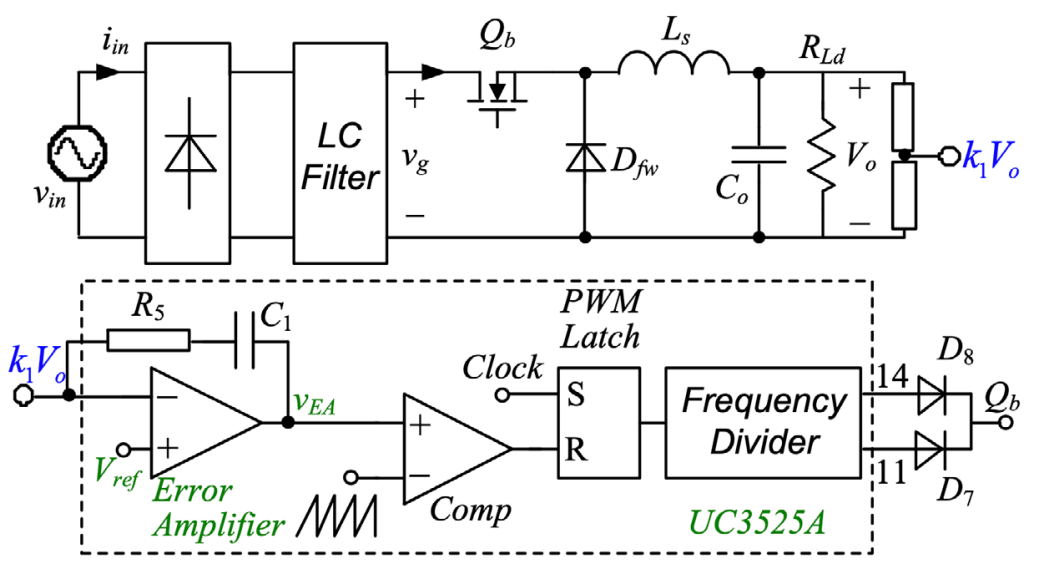

Figure 1. Buck converter with CDC control scheme.

Source: (Yao et al., 2017).

$$
v_{i n}(\theta)=v_{g}=\sqrt{2} V_{r m s} \sin \theta
$$

Where $V_{r m s}$ is the rms value.

There are three switching cycles when buck converter works in discontinuous conduction mode (DCM).

When $Q_{b}$ conducts, the inductor is getting charge from supply voltage in first switching cycle as depicted in Figure 2.

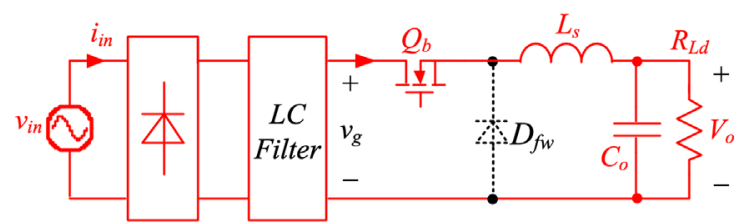

Figure 2. Buck converter during first switching cycle.

Source: (Yao et al., 2017).

The peak current of inductor $i_{L_{-} p k}$ is given as

$$
i_{L_{-} p k}=\frac{\sqrt{2} V_{r m s} \sin \theta-V_{o}}{L_{s}} D_{o n} T_{s}
$$

Where $D_{\text {on }}$ is the duty-cycle of during turn on time of switch

When $Q_{b}$ is off, inductor is discharging through load and output capacitor, as shown in in Figure 3. It occurs in second switching cycle 


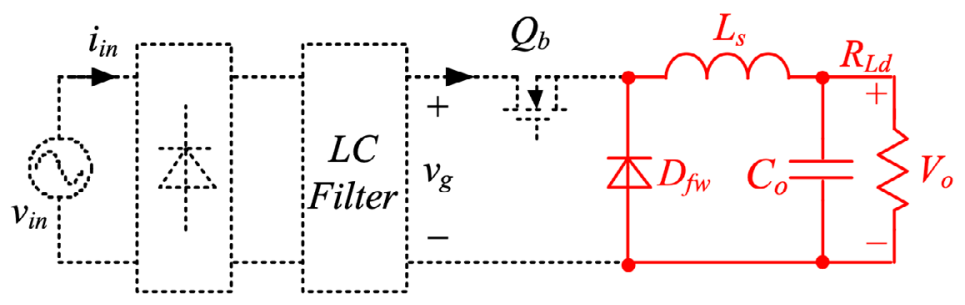

Figure 3. Buck converter during second switching cycle.

Source: (Yao et al., 2017).

The peak current of inductor $i_{L_{-} p k}$ is

$$
i_{L_{-} p k}=-\frac{V_{o}}{L_{s}} D_{o n} T_{s}
$$

By using the information of volt-second balance, following expression is obtained

$$
\left(\sqrt{2} V_{r m s} \sin \theta-V_{o}\right) D_{o n} T_{s}=V_{o} D_{o f f} T_{s}
$$

From (2) and (4), the following relation is obtained

$$
D_{o f f}=\frac{\sqrt{2} V_{r m s} \sin \theta-V_{o}}{V_{o}} D_{o n}
$$

During third switching cycle, output capacitor is discharged through load as shown in Figure 4.

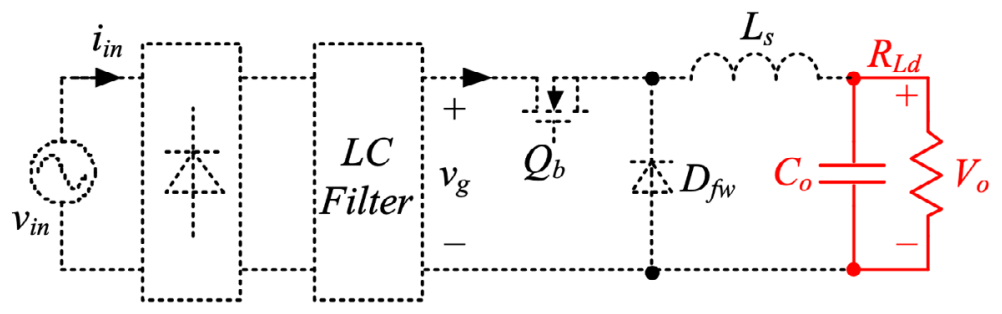

Figure 4. Buck converter during third switching cycle.

Source: (Yao et al., 2017).

The value of average input current for buck converter is got as

$$
i_{b_{-} \text {ar } \_ \text {dctec }}=\frac{D_{o n}{ }^{2}\left(\sqrt{2} V_{r m s} \sin \theta-V_{o}\right)}{2 L_{s} f_{s}}
$$

For complete half cycle, input current is expressed as 


$$
i_{i n_{-} b_{-} c d c c s}= \begin{cases}\frac{D_{o n}{ }^{2}\left(\sqrt{2} V_{r m s} \sin \theta-V_{o}\right)}{2 L_{s} f_{s}} & \theta_{0}<\theta<\pi-\theta_{0} \\ 0 & 0 \leq \theta<\theta_{0} \& \pi-\theta_{0}<\theta \leq \pi\end{cases}
$$

Where $\theta_{0}=\arcsin V_{o} /$ sqrt $2 * V_{r m s}$

Based on (1) and (7), the input power of the buck converter is expressed as

$$
P_{i n_{-} c d c c s}=\frac{\sqrt{2} V_{r m s} D_{o n}^{2}}{2 \pi L_{s} f_{s}} \int_{\theta_{0}}^{\pi-\theta_{o}} \sin \theta\left(\sqrt{2} V_{r m s} \sin \theta-V_{o}\right) d \theta
$$

Now $D_{\text {on }}$ can be calculated by assuming the efficiency of buck converter as $100 \%$

$$
D_{o n}=\sqrt{\frac{2 \pi L_{s} f_{s} P_{o}}{\sqrt{2} V_{r m s} \int_{\theta_{0}}^{\pi-\theta_{o}} \sin \theta\left(\sqrt{2} V_{r m s} \sin \theta-V_{o}\right) d \theta}}
$$

\section{PROPOSED VDC CONTROL SCHEME FOR BUCK CONVERTER FOR EFFICIENCY IMPROVEMENT}

\subsection{VDC CONTROL SCHEME FOR EFFICIENCY IMPROVEMENT}

For obtaining, high efficiency, the variation rule for duty-cycle must be

$$
D_{\text {on_vdccs }}=\sqrt{\frac{D_{c} V_{m} \sin \theta}{\sqrt{2} V_{r m s} \sin \theta-V_{o}}}
$$

Where Dc is a co-efficient,

By substituting the value of $D_{\text {on }}$ in (6), we obtain

$$
i_{i n_{-} b_{-} v d c c s}=\frac{\sqrt{2} V_{r m s} \sin \theta D_{c} T_{s}}{2 L_{s}}
$$

The average value of input power with VDC control scheme is expressed as

$$
P_{i n_{-} b_{-} \text {vdccs }}=\frac{1}{\pi} \int_{\theta_{0}}^{\pi-\theta_{0}} \frac{D_{c} T_{s}\left(\sqrt{2} V_{r m s} \sin \theta\right)^{2}}{2 L_{s}} d \theta=P_{o}
$$

The value of $D_{c}$ is got from (12) as

$$
D_{c}=\frac{4 \pi L_{s} P_{o}}{\left(\sqrt{2} V_{r m s}\right)^{2}\left(\pi-2 \theta_{0}+\sin 2 \theta_{0}\right) T_{s}}
$$

By substituting the value of $D_{c}$ in (11), we get

$$
D_{\text {on_vddcs }}=\sqrt{\frac{4 \pi P_{o} L_{s} \sin \theta}{\left(\pi-2 \theta_{0}+\sin 2 \theta_{0}\right)\left(\sqrt{2} V_{r m s} \sin \theta-V_{o}\right) \sqrt{2} \mathrm{~V}_{r m s} T_{s}}}
$$




\subsection{FITTING VDC CONTROL SCHEME}

For the implementation of Don_vdccs, it is essential to remove squire root term from (14). Because it is difficult to realize to it by using analogue circuits.

Defining $a=V_{m} / V_{\partial}, y=\sin \theta$, eq. (14) can be simplified as

$$
\begin{aligned}
& \qquad D_{o n_{-} f i t}=D_{1}\left(1-\frac{y}{2 a y_{0}^{2}-y_{0}}\right) \\
& \text { where } D_{1}=\sqrt{\frac{D_{0} a y_{0}}{a y_{0}-1}} \frac{2 a y_{0}-1}{2\left(a y_{0}-1\right)} . \\
& y_{0}=0.75
\end{aligned}
$$

Eq. 15 can be rewritten as

$$
D_{o n_{-} f i t}=D_{1} \frac{1.125 V_{m}-0.75 V_{o}-V_{o} \sin \theta}{1.125 V_{m}-0.75 V_{o}}
$$

The average input current with VDCCS is given as

$$
i_{b_{-} \text {VDCCS }}=\frac{\left(\sqrt{2} V_{r m s} \sin \theta-V_{o}\right)}{2 L_{s} f_{s}} D_{o n_{-} f i t}^{2}
$$

\section{EFFICIENCY COMPARISON}

\subsection{LOSS DUE TO BRIDGE DIODE RECTIFIER}

The loss caused by bridge diode rectifier is calculated as below

$$
\begin{aligned}
& P_{c o n \_b r i d g e(d d c c s)}=2 V_{F D} I_{\text {in_avg(cdccs })} \\
& P_{\text {con_bridge(vdccs) }}=2 V_{F D} I_{\left.i n_{-} \text {avg(vdccs }\right)}
\end{aligned}
$$

KBL10 is adopted as the rectifier bridge, whose forward voltage drop VFD is $0.9 \mathrm{~V}$.

The input current with CDC control scheme and VDC control scheme is given as

$$
i_{b_{-} \text {dces }}=\frac{2 \pi L_{s} f_{s} P_{o}\left(\sqrt{2} V_{r m s} \sin \theta-V_{o}\right)}{2 \sqrt{2} L_{s} f_{s} V_{r m s} \int_{\theta_{0}}^{\pi-\theta_{o}} \sin \theta\left(\sqrt{2} V_{r m s} \sin \theta-V_{o}\right) d \theta}
$$




$$
i_{b_{-} \text {vades }}=\frac{\left(D_{1} \sqrt{\frac{D_{0} a y_{0}}{a y_{0}-1}} \frac{2 a y_{0}-1}{2\left(a y_{0}-1\right)} \frac{1.125 V_{m}-0.75 V_{o}-V_{o} \sin \theta}{1.125 V_{m}-0.75 V_{o}}\right)^{2}\left(\sqrt{2} V_{r m s} \sin \theta-V_{o}\right)}{2 L_{s} f_{s}}
$$

\subsection{CONDUCTION LOSSES OF THE SWITCHES}

The rms current of the on time period, i.e., the rms current of switch $Q_{b}$ can be got as

$$
I_{r m s\left(Q b_{-} o n\right)}=\sqrt{\frac{\int_{\theta_{0}}^{\pi-\theta_{0}} i_{L_{-} p k}^{2} D_{o n} d \theta}{3 \pi}}
$$

The rms current of the off time period can be determined as

$$
I_{r m s\left(Q b_{-} o f f\right)}=\sqrt{\frac{\int_{\theta_{0}}^{\pi-\theta_{0}} i_{L_{-} p k}^{2} D_{o f f} d \theta}{3 \pi}}
$$

While $Q_{b}$ is on and off, the current flows through the winding of the inductor, whose rms current is

$$
\begin{aligned}
& I_{r m s(c d c c s)}=\sqrt{I_{r m s\left(Q b_{-} o n_{-} c d c c s\right)}^{2}+I_{r m s\left(Q b_{-} o f f \_c d c c s\right)}^{2}} \\
& I_{r m s(v d c c s)}=\sqrt{I_{r m s\left(Q b_{-} o n_{-} v d c c s\right)}^{2}+I_{r m s\left(Q b_{-} o f f \_v d c c s\right)}^{2}}
\end{aligned}
$$

The losses due to conduction of switches can be got as

$$
\begin{aligned}
& P_{c o n_{-} s w i t c h e s(c d c c s)}=I_{r m s\left(Q b_{-} o n_{-} c d c c s\right)}^{2} R_{D S(o n)_{-} S} \\
& P_{c o n \_s w i t c h e s(v d c c s)}=I_{r m s\left(Q b_{-} o n_{-} v d c c s\right)}^{2} R_{D S(o n)_{-} S}
\end{aligned}
$$

The value of $R_{D S(O n)} 0.19 \Omega$ which is found from datasheet of 20 N60C3.

\subsection{LOSSES DUE TURN OFF SWITCHES}

The loss caused by turning off the switch with CDC control scheme and VDC control scheme is calculated as

$$
P_{o f f_{-} \text {switches(cdccs) }}=\frac{T_{s} t_{f}}{2 \pi} \int_{0}^{\pi} i_{L_{-} p k_{-} c d c c s}\left(V_{m} \sin \theta\right) d \theta
$$




$$
P_{o f f_{-} \text {switches }(v d c c s)}=\frac{T_{s} t_{f}}{2 \pi} \int_{0}^{\pi} i_{L_{-} p k_{-} v d c c s}\left(V_{m} \sin \theta\right) d \theta
$$

Where $t_{f}$ value is $12 \mathrm{~ns}$ for CMOS 20N60C.

\subsection{THE LOSS CAUSED BY COPPER OF THE INDUCTOR}

The inductor's copper loss with CDCGS and VDCGS can be found below as

$$
\begin{aligned}
& P_{\text {copper }(\mathrm{cdccs})}=I_{r m s(\mathrm{cdccs}) L f}^{2} R_{\text {copper }(L f)}+I_{r m s(\mathrm{cdccs}) H f}^{2} R_{\text {copper }(H f)} \\
& P_{\text {copper }(\text { vddcs })}=I_{r m s(\text { vdces }) L f}^{2} R_{\text {copper }(L f)}+I_{r m s(\text { vdccs }) H f}^{2} R_{\text {copper }(H f)}
\end{aligned}
$$

Where $R_{\text {copper }(L f)}$ is 0.16 and $R_{\text {copper }(H f)}$ is 0.23 .

The low frequency and high frequency of rms current can be found out by using below formula

$$
\begin{gathered}
I_{r m s_{-} f}=\sqrt{\frac{1}{\pi} \int_{0}^{\pi} i_{L_{-} a v e}^{2} d \theta}=\sqrt{\frac{1}{\pi} \int_{0}^{\pi}\left[\frac{D_{y}^{2} T_{s} v_{g}\left(v_{g}-V_{o}\right)}{2 L_{b} V_{o}}\right]^{2} d \theta} \\
i_{r m s_{-} h f}=\sqrt{\frac{1}{T_{s}} \int_{0}^{T_{s}}\left(i_{L}(t)-i_{L_{-} a v e}\right)^{2} d t} \\
I_{r m s_{-} h f}=\sqrt{\frac{1}{\pi} \int_{0}^{\pi} i_{r m s_{-} h f}^{2} d \theta}
\end{gathered}
$$

\subsection{LOSS DUE TO CORE OF THE INDUCTOR}

The loss caused by core of inductor with CDCGS and VDCGS is calculated as

$$
\begin{gathered}
P_{\text {core }(\text { cdccs })}=\left[\int_{0}^{\pi} C_{m} f_{s(\text { cdccs })}{ }^{x} B_{a c(c d c s)}{ }^{y}\left(c t_{0}-c t_{1} T_{a}-c t_{2} T_{a}^{2}\right) d \theta\right] \frac{10^{3} V_{e}}{\pi} \\
B_{a c(\text { cdccs })}=\frac{L i_{L_{-} p k_{-} \text {ddcs }}}{2 N A_{e}}
\end{gathered}
$$




$$
\begin{gathered}
P_{\text {core }(v d c c s)}=\left[\int_{0}^{\pi} C_{m} f_{s(v d c s)}{ }^{x} B_{a c(v d c c s)}{ }^{y}\left(c t_{0}-c t_{1} T_{a}-c t_{2} T_{a}^{2}\right) d \theta\right] \frac{10^{3} V_{e}}{\pi} \\
B_{a c(v d c c s)}=\frac{L i_{L_{-} p k_{-} v d c c s}}{2 N A_{e}}
\end{gathered}
$$

The value of core parameters can be found from [24].

\subsection{THE LOSS DUE TO CONDUCTION OF THE FREEWHEELING DIODE}

The conduction loss due to freewheeling diode with GDC and VDC control scheme is

$$
\begin{aligned}
& P_{\text {con_freewheelingdiode }(c d c c s)}=\frac{V_{F D_{f w}}}{\pi} \int_{0}^{\pi} \frac{i_{p k(c d c c s)}}{2} D_{o f f} d \theta \\
& P_{\text {con_freewheelingdiode(vdccs) }}=\frac{V_{F D_{f w}}}{\pi} \int_{0}^{\pi} \frac{i_{p k(v d c c)}}{2} D_{o f f} d \theta
\end{aligned}
$$

The value of VFD is 0.67 for MUR 860 diode.

\subsection{THE EFFICIENCY COMPARISON}

The efficiency of DCM buck converter with CDG and VDG control scheme can be calculated as

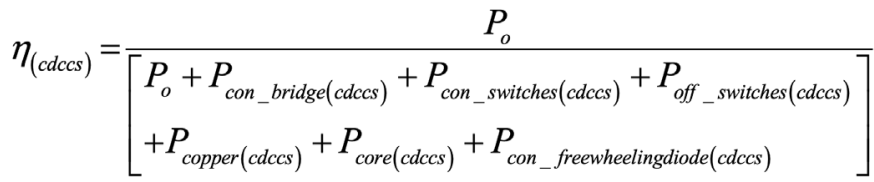

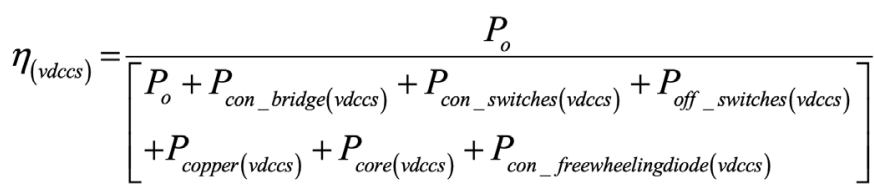

From above equations and parameters of converter, the theoretical efficiency of converter with CDC and VDC control scheme is calculated and compared as shown in Figure 5. It can be concluded that efficiency of DCM buck converter has improved in case of VDC control scheme. 


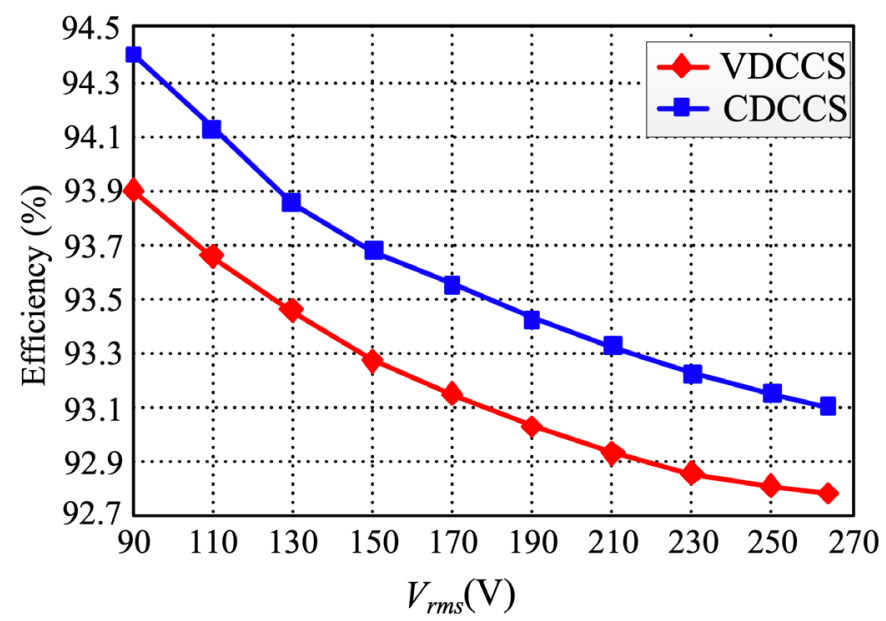

Figure 5. Efficiency at universal input voltage. Mathcad eq: (16-29).

\section{SIMULATION RESULTS}

For verifying the effectiveness of VDCCS strategy, simulations are carried out. The input voltage range is $90-264 \mathrm{VAC}$, and the output is $80 \mathrm{~V}$. For ensuring the current to be in DCM, UC3525A IC is used. All the components in the circuit are selected as idea.

Figure 6 and Figure 7 show the simulation waveforms of input voltage, input current and output voltage of DCM buck converter with CDCCS and VDCCS at 220VAC inputs, respectively. It can be seen that the input current with VDCCS has less peaks as compared to input current with CDCGS is more sinusoidal as compared with CDCG.

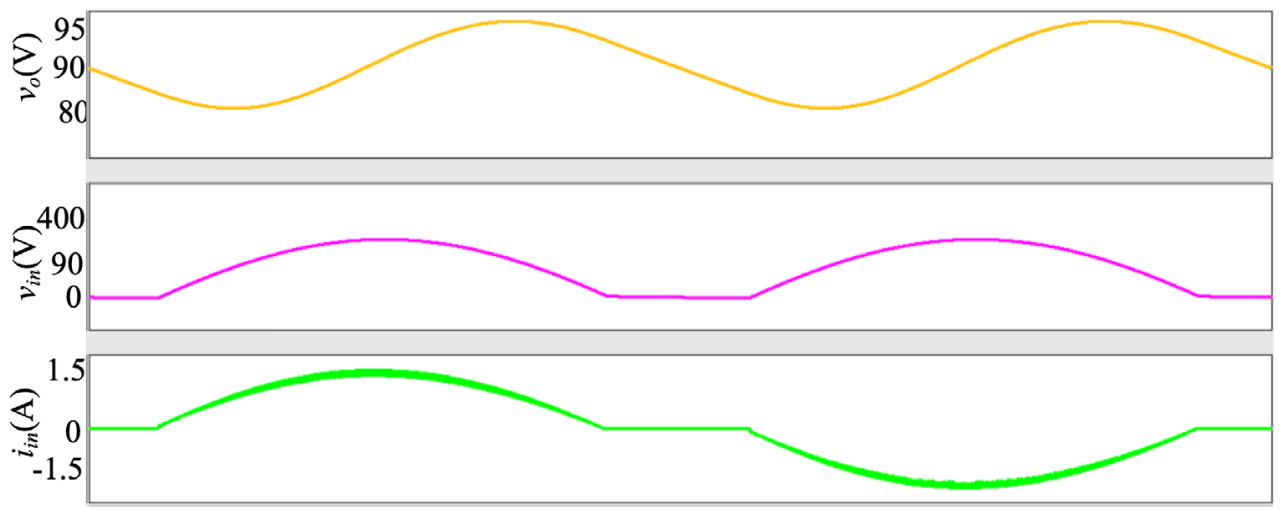

Figure 6. $v_{\mathrm{o}}$, and $\mathrm{v}_{\mathrm{in}}, \mathrm{i}_{\mathrm{in}}$ with CDC control scheme [Simulation waveform from Saber Software]. 


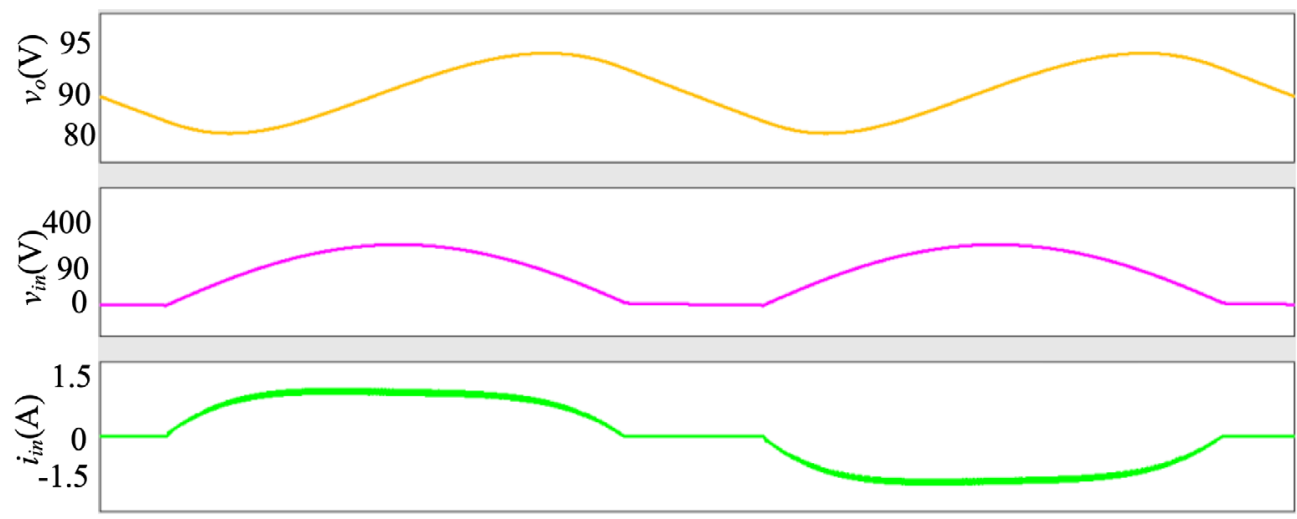

Figure 7. $v_{0}$, and $v_{\text {in }}, i_{\text {in }}$ with VDC control scheme [Simulation waveform from Saber Software].

\section{CONCLUSIONS}

Electronic devices require $\mathrm{AC}$ to $\mathrm{DC}$ converter (rectifier) to convert $\mathrm{AC}$ voltage from the grid to $\mathrm{DC}$ voltage for the electronics and its result is low power factor $(\mathrm{PF})$ and harmonic current injection into the system. Nowadays, power factor correction (PFC) converters are being widely used which can achieve high power factor $(\mathrm{PF})$ and reduce the harmonics caused during AC to DG conversion and discontinuous conduction mode (DCM) buck PFC converter is one of mostly used converter. The DGM buck converter is generally utilized in many applications because of various advantages like maintaining high efficiency for the wide range of input voltage, cost reduction, low output voltage, protection against inrush current and life time improvement. However, its efficiency is low when operated with constant duty-cycle control scheme. For increasing the efficiency and ultimately reducing the losses of the DCM buck converter, a variable duty-cycle control scheme has been introduced. Fitting duty-cycle method is also discussed to make circuit implementation easier. For verifying the validity of proposed technique, the simulation results are carried out.

\section{REFERENCES}

Al Gabri, A. M., Fardoun, A. A., \& Ismail, E. H. (2015). Bridgeless PFC-modified SEPIC rectifier with extended gain for universal input voltage applications. IEEE Transactions on Power Electronics, 30(8), 4272-4282. http://doi.org/10.1109/TPEL.2014.2351806 
Anwar, U., Erickson, R., Maksimović, D., \& Afridi, K. K. (2017). A control architecture for low current distortion in bridgeless boost power factor correction rectifiers. In 2017 IEEE Applied Power Electronics Conference and Exposition (APEC) (pp. 82-87). IEEE. http://doi.org/10.1109/APEG.2017.7930676

Badawy, M. O., Sozer, Y., \& De Abreu-Garcia, J. A. (2016). A novel control for a cascaded buck-boost PFC converter operating in discontinuous capacitor voltage mode. IEEE Transactions on Industrial Electronics, 63(7), 4198-4210. http://doi. org/10.1109/TIE.2016.2539247

Endo, H., Yamashita, T., \& Sugiura, T. (1992). A high-power-factor buck converter. In PESC'92 Record. In 23rd Annual IEEE Power Electronics Specialists Conference (pp. 10711076). IEEE. http://doi.org/10.1109/TPEL.2010.2068060

Erickson, R. W., \& Maksimovic, D. (2007). Fundamentals of power electronics. Springer Science \& Business Media. https://www.springer.com/gp/book/9781475705591

Huber, L., Gang, L., \& Jovanovic, M. M. (2009). Design-oriented analysis and performance evaluation of buck PFC front end. IEEE Transactions on power electronics, 25(1), 85-94. http://doi.org/10.1109/TPEL.2009.2024667

Jang, Y., \& Jovanović, M. M. (2011). Bridgeless high-power-factor buck converter. IEEE Transactions on Power Electronics, 26(2), 602-611. http://doi.org/10.1109/ TPEL.2010.2068060

Ki, S. K., \& Lu, D. D. G. (2012). A high step-down transformerless single-stage singleswitch AC/DC converter. IEEE Transactions on Power Electronics, 28(1), 36-45. http:// doi.org/10.1109/TPEL.2012.2195505

Lamar, D. G., Fernandez, M., Arias, M., Hernando, M. M., \& Sebastian, J. (2012). Tapped-inductor buck HB-LED AC-DC driver operating in boundary conduction mode for replacing incandescent bulb lamps. IEEE Transactions on Power Electronics, 27(10), 4329-4337. http://doi.org/10.1109/TPEL.2012.2190756 
Lee, Y. S., Wang, S. J., \& Hui, S. Y. R. (1997). Modeling, analysis, and application of buck converters in discontinuous-input-voltage mode operation. IEEE Transactions on Power Electronics, 12(2), 350-360. http://doi.org/10.1109/63.558762

Liu, X., Wan, Y., He, M., Zhou, Q., \& Meng, X. (2020). Buck-Type Single-Switch Integrated PFC Converter With Low Total Harmonic Distortion. IEEE Transactions on Industrial Electronics, 6. http://doi.org/10.1109/TIE.2020.3007121

Memon, A. H., \& Yao, K. (2018a). UPC strategy and implementation for buck-buck/ boost PF correction converter. IET Power Electronics, 11(5), 884-894. http://doi. org/10.1049/iet-pel.2016.0919

Memon, A. H., Baloach, M. H., Sahito, A. A., Soomro, A. M., \& Memon, Z. A. (2018b). Achieving High Input PF for CRM Buck-Buck/Boost PFC Converter. IEEE Access, 6, 79082-79093. http://doi.org/10.1109/ACGESS.2018.2879804

Memon, A. H., Memon, M. A., Memon, Z. A., \& Hashmani, A. A. (2019a). Critical Conduction Mode Buck-Buck/Boost Converter with High Efficiency. 3C Tecnología. Glosas de innovación aplicadas a la pyme. Edición Especial, Noviembre 2019, 201-219. http:// dx.doi.org/10.17993/3ctecno.2019.specialissue3.201-219

Memon, A. H., Memon, Z. A., Shaikh, N. N., Sahito, A. A., \& Hashmani, A. A. (2019b). Boundary conduction mode modified buck converter with low input current total harmonic distortion. Indian Fournal of Science and Technology, 12, 17. https://doi. org/10.17485/ijst/2019/v12i17/144613

Memon, A. H., Nizamani, M. O., Memon, A. A., Memon, Z. A., \& Soomro, A. M. (2019c). Achieving High Input Power Factor for DCM Buck PFC Converter by Variable Duty-Cycle Control. 3C Tecnología. Glosas de innovación aplicadas a la pyme. Edición Especial, Noviembre 2019, 185-199. http://dx.doi.org/10.17993/3ctecno.2019. specialissue3.185-199

Memon, A. H., Noonari, F. M., Memon, Z., Farooque, A., \& Uqaili, M. A. (2020a). $\mathrm{AC} / \mathrm{DC}$ critical conduction mode buck-boost converter with unity power factor. $3 C$ 
Tecnología. Glosas de innovación aplicadas a la pyme. Edición Especial, Abril 2020, 93-105. http:/ / doi.org/10.17993/3ctecno.2020.specialissue5.93-105

Memon, A. H., Pathan, A. A., Kumar, M., \& Sahito, A. J., \& Memon, Z. A. (2019d). Integrated buck-flyback converter with simple structure and unity power factor. Indian Fournal of Science and Technology, 12, 17. https://doi.org/10.17485/ijst/2019/ v12i17/144612

Memon, A. H., Shaikh, N. N., Kumar, M., \& Memon, Z. A. (2019e). Buck-buck/boost converter with high input power factor and non-floating output voltage. International Journal of Computer Science and Network Security, 19(4), 299-304. http://paper.ijcsns. org/07_book/201904/20190442.pdf

Memon, A. H., Yao, K., Ghen, Q., Guo,J., \& Hu, W. (2016). Variable-on-time control to achieve high input power factor for a CRM-integrated buck-flyback PFC converter. IEEE Transactions on Power Electronics, 32(7), 5312-5322. http://doi.org/10.1109/ TPEL.2016.2608839

Memon, A. H., Samejo,J. A., Memon, Z. A., \& Hashmani, A. A. (2020b). Realization Of Unity Power Factor For Ac/Dc Boundary Conduction Mode Flyback Converter With Any Specific Turn's Ratio. Journal of Mechanics Of Continua And Mathematical Sciences, (spl6). https://doi.org/10.26782/jmcms.spl.6/2020.01.00014

Memon, A. H., Shaikh, S. A., Memon, Z. A., Memon, A. A., \& Memon, A. A. (2020c). DCM Boost Converter with High Efficiency. Journal Of Mechanics Of Continua And Mathematical Sciences, (spl6). https://doi.org/10.26782/jmcms.spl.6/2020.01.00006

Nussbaumer, T., Raggl, K., \& Kolar, J. W. (2009). Design guidelines for interleaved single-phase boost PFG circuits. IEEE Transactions on Industrial Electronics, 56(7), 25592573. https://doi.org/10.1109/TIE.2009.2020073

Praneeth, A. V. J. S., \& Williamson, S. S. (2018). A review of front end ac-dc topologies in universal battery charger for electric transportation. In 2018 IEEE Transportation Electrification Conference and Expo (ITEC) (pp. 293-298). https://doi.org/10.1109/ ITEG.2018.8450186 
Spiazzi, G., \& Buso, S. (2000). Power factor preregulators based on combined buckflyback topologies. IEEE transactions on Power Electronics, 15(2), 197-204. https://doi. org/10.1109/63.838091

Williamson, S. S., Rathore, A. K., \& Musavi, F. (2015). Industrial electronics for electric transportation: Current state-of-the-art and future challenges. IEEE Transactions on Industrial Electronics, 62(5), 3021-3032. https://doi.org/10.1109/TIE.2015.2409052

Yao, K., Zhou, X., Yang, F., Yang, S., Gao, G., \& Mao, G. (2017). Optimum third current harmonic during nondead zone and its control implementation to improve PF for DGM buck PFG converter. IEEE Transactions on Power Electronics, 32(12), 92389248. https://doi.org/1109/TPEL.2017.2657883 